Article

\title{
Permanent Mould Thin Slab Casting and Heat Tretment of 8\% Chromium Cold Work Tool Steel (AISI DC 53)
}

\author{
İsmail Seçkin Çardaklı * and Ali Kalkanlı
}

\section{Department of Metallurgical and Materials Engineering, Middle East Technical University, Ankara 06800, Turkey; kalkanli@metu.edu.tr}

*Correspondence: cardakli@metu.edu.tr; Tel.: +90-505-929-1417

\begin{abstract}
In this study, an alternative method to conventional production methods involving thin section copper permanent mould casting (rapid solidification), hot rolling and heat treatment processes to manufacture AISI DC 53 cold work tool steel, has been investigated. In this new method, solidification of the AISI DC 53 was done in the thin section copper mould instead of traditional ingot casting. After solidification, thin slabs obtained was homogenized to $1150{ }^{\circ} \mathrm{C}$ and hold at this temperature for one hour and then hot rolling was be applied. During hot rolling process, about \% 30 reduction in thickness of slab was obtained. After hot rolling, heat treatment (austenitizing, quenching and tempering) have been applied to thin slab. The samples have been taken as cast, as rolled and as heat treated (austenitized and tempered) and the microstructural analysis, hardness tests, retained austenite quantity measurement by XRD method have been performed. The heat treatment and tests have been performed for a commercially available AISI DC 53 which is manufactured by thick section ingot casting and rolling. Hardness values of the AISI DC 53 steels produced by traditional route is in the range of 52-54 HRC after austenitization at $1025{ }^{\circ} \mathrm{C}$ for one hour and quenched in compressed air and tempered twice at $525{ }^{\circ} \mathrm{C}$ for 120 mins. On contrary the permanent mould cast AISI DC 53 after homogenization at $1150{ }^{\circ} \mathrm{C}$ and immediately hot rolling then air cooling and austenitized at $1025{ }^{\circ} \mathrm{C}$ for one hour then quenched by compressed air and tempered twice at $525{ }^{\circ} \mathrm{C}$ for 120 mins have hardness valeus in the range of 55-57 HRC. Experiments have revealed that the properties of new rapid solidified steel in permanent copper mould are better than the commercially available steel and have a more refined
\end{abstract}


microstructure than commercially produces alternative. Therefore, the new proposed method can be used as an alternative manufacturing method for cold-work tool steels.

Keywords: AISI DC53; rapid solidification; retained austenite measurement

\section{Introduction}

Tool steel is a variety of carbon and alloy steels used for cutting, blanking, stamping and coining applications. Their superior properties as high hardness, high abrasion and wear resistance comes from carbide structures in a hard and tough matrix. Generally tool steel consists of $0.5 \%$ and $1.5 \%$ carbon content and four major alloying elements which are tungsten, chromium, vanadium and molybdenum. These alloy elements have high affinity to combine with carbon in order to form carbides. At the final stage of solidification because of segregation, grain boundaries saturated by carbon and chromium transforme to a skeletal coarse morphology of metallic carbides [1] which provide high hardness, high abrasion and wear resistance for cold work applications stated above. But they are also stress concentration points during loading and cause brittle fracture of these materials during service life. Large and coarse primary after solidification are changed into fine carbides and more homogeneous distribution in the matrix by thermomechanical (forging \& rolling) processes [2-4]. However, these conventional routes (casting and forging \& rolling) consume a lot of energy, time and money. Consequently, alternative methods of production of these materials with high strength and toughness as well as high resistance to fatigue is needed [5].

In the recent years, research works relating to solidification of cast alloys with high cooling rate have come to be progressively more important. Compared with conventional casting techniques, rapidly solidified cast products have a very good mechanical properties, which is basically due to finer grains and homogenous microstructures. By refining the microstructure of cast alloys, the mechanical performance would be improved.

\section{Materials and Methods}

The chemical compositions of the tool steel used as a testing alloy are indicated in table 1. The melt of tool steel was prepared using an air atmosphere induction furnace. Firstly the melt was poured at $1550{ }^{\circ} \mathrm{C}$ in thin section copper mould. To control segregation during 
solidification, copper mould was heated to about $200{ }^{\circ} \mathrm{C}$. The dimensions of as-cast slab samples were $300 \mathrm{~mm} * 60 \mathrm{~mm} * 7 \mathrm{~mm}$. After homogenization at $1150{ }^{\circ} \mathrm{C}$ and immediately hot rolling then air cooling and austenitized at $1025{ }^{\circ} \mathrm{C}$ for one hour then quenched by compressed air and tempered twice at $525{ }^{\circ} \mathrm{C}$ for 30, 60, 90 and 120 mins. During permanent mould castings thermal analysis were performed after casting of liquid steel into resin bonded Heraeus Electronite Quik cup having Pt-10\%Rh thermocouples and recording temperature time data by a data logger Elimko 680 for further cooling curve analysis. The data were processed by Matlab 2008 for obtaining first derivatives to determine liquidus and carbide precipitaion start and finish temperatures.

Microstructural examinations were done as-cast, as-rolled and heat treated samples by optical microscope and X-ray diffraction. Etchant reagent was Picral for the samples. The carbide extraction was performed by leaching tool steel in $37 \%$ purity $\mathrm{HCl}$ acid to reveal carbide type by XRD. Hardness tests were performed to heat treated samples by Universal Emco M4U-025 hardness testing machine.

Table 1. Chemical composition of the steel used (mass\%).

\begin{tabular}{|c|c|c|c|c|c|c|c|}
\hline & $\mathrm{C}$ & $\mathrm{Cr}$ & $\mathrm{Mn}$ & $\mathrm{Si}$ & $\mathrm{Mo}$ & $\mathrm{V}$ & $\mathrm{Fe}$ \\
\hline Steel & 0.9 & 7.8 & 0.5 & 0.9 & 2.5 & 0.5 & Bal. \\
\hline
\end{tabular}

\section{Results and Discussion}

\subsection{Solidification of AISI DC 53}

The cooling curve (Figure 1) shows that solidification of $8 \% \mathrm{Cr}$ cold work tool steel starts by the nucleation and growth of austenite dendrites at approximately $1418{ }^{\circ} \mathrm{C}$. Solidification is ends up with the hundred percentage of austenite phase. At the final stage of solidification because of segregation, grain boundaries saturated by carbon and chromium transformed to interdendritic skeletal morphology of primary carbides. The start and finish temperatures of carbide precipitation obtained first derivative of cooling curve are approximately $1148{ }^{\circ} \mathrm{C}$ and $850{ }^{\circ} \mathrm{C}$. Optical microscopy analysis (Figure 2) and diffraction pattern (Figure 3) taken from cross-section of sample revealed the presence of metastable austenite, primary carbides and some amount of alpha-phase (martensite). Diffraction pattern of the carbide extraction replicas (Figure 4) shows that interdendritic carbides are $\mathrm{Cr}$ based $\mathrm{M}_{7} \mathrm{C}_{3}$ carbides. Any eutectic reaction is not observed during solidification. 


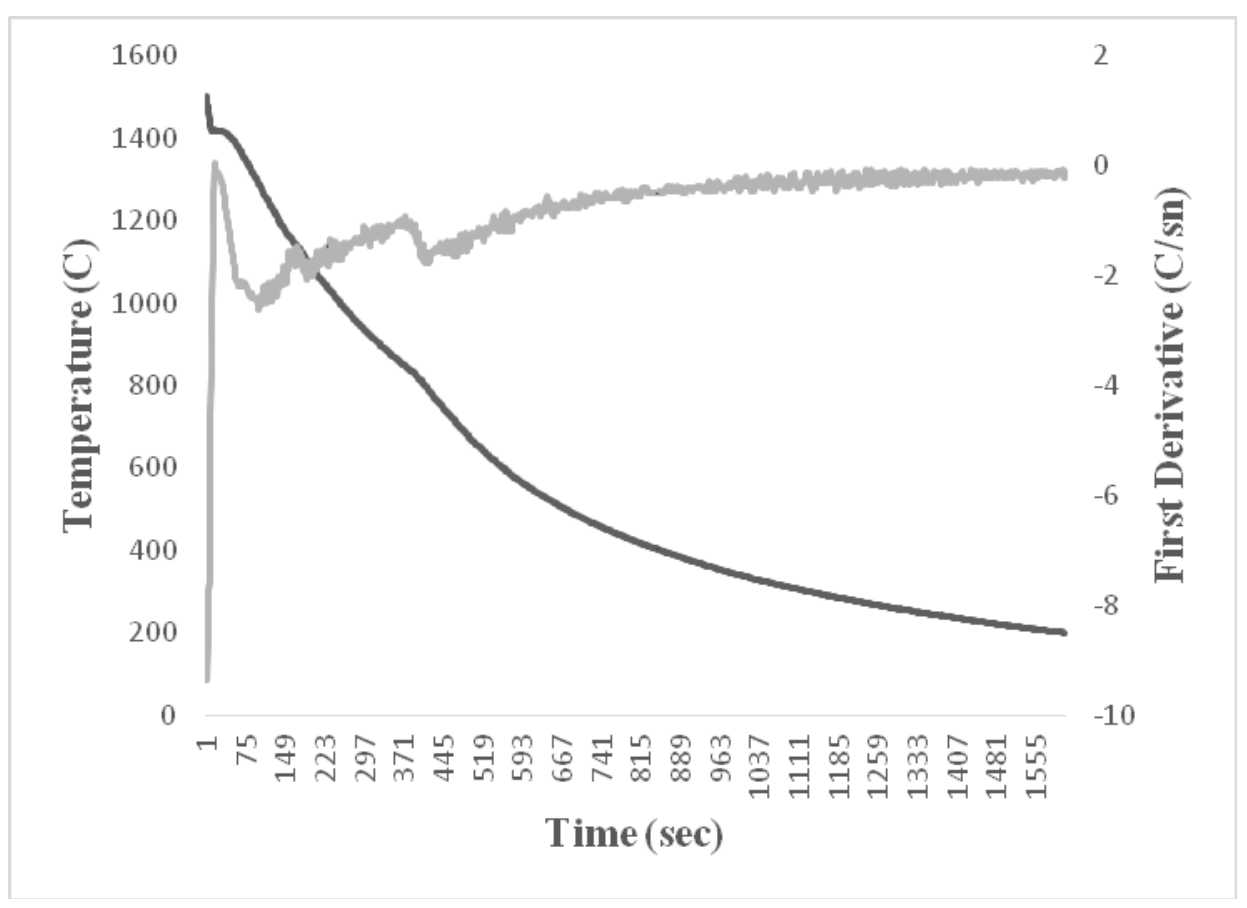

Figure 1. Cooling curve and first derivative of DC 53 steel

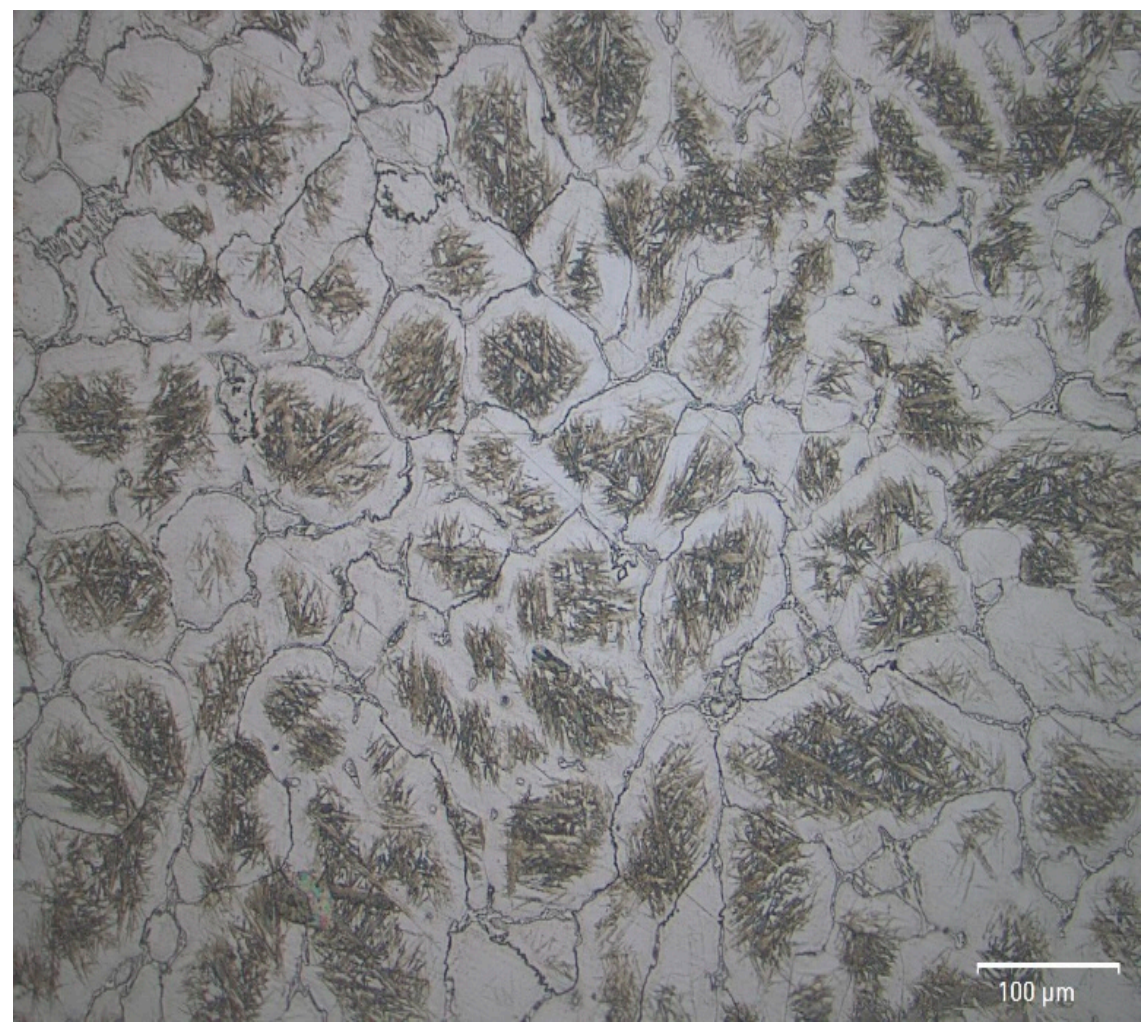

Figure 2. As-cast microstructure of DC 53 


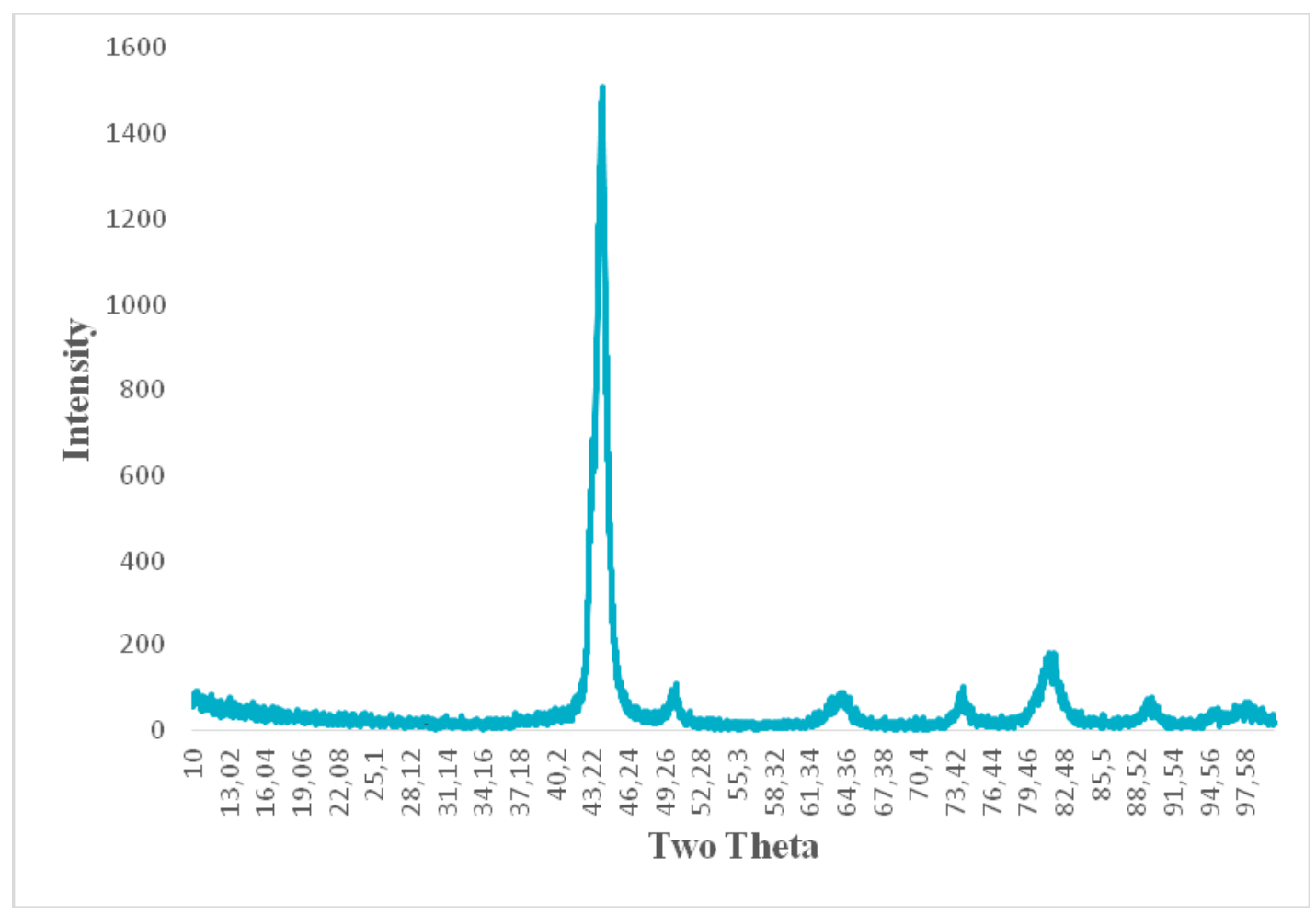

Figure 3. XRD pattern of as-cast DC 53 steel

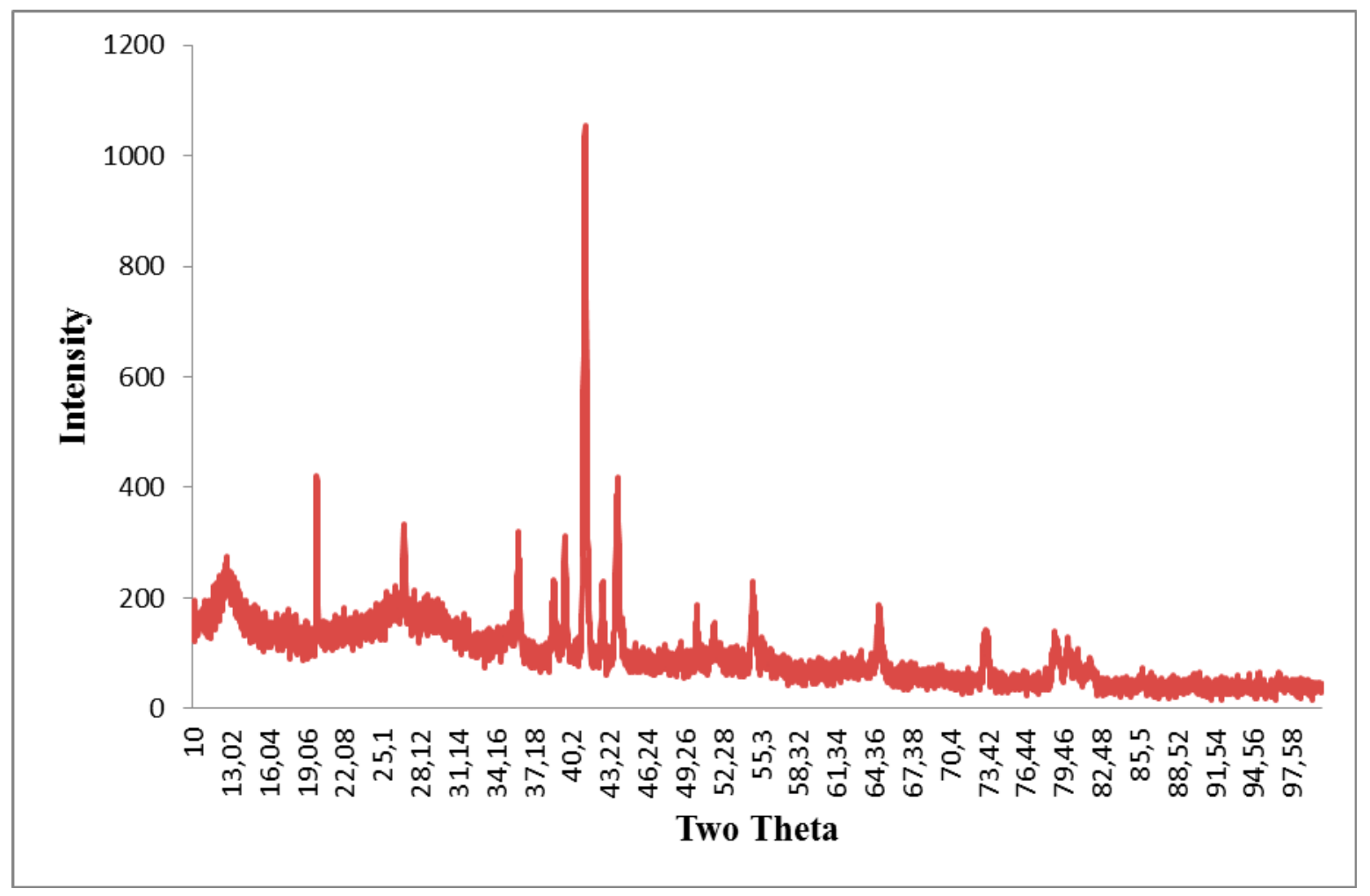

Figure 4. XRD pattern of extracted replicas of carbides 


\subsection{Microstructure \& Retained Austenite Amount}

Retained austenite (white regions) and martensite phases (dark regions) exist in as cast sample (Figure 5 and 6). Rapid solidification of $8 \% \mathrm{Cr}$ tool steel causes the supersaturation of austenite with carbon and alloying elements by low segregation and the decrease of martensite-start temperature of steel. Hence, steel matrix consists of a large amount of retained austenite at room temperature. Optical micrograph of as-rolled steel (Figure 7 and 8) shows that primary dendritic structure changes completely to non dendritic and homogeneous structure of martensite (dark regions) and metastable austenite (white regions). The amounts of retained austenite are measured by XRD method [6,7]. The volume of retained austenite at as-cast sample and as-rolled sample are about 59,82\% and 40,68\% respectively. Retained austenite amount decreased during homogenization annealing because of diffusion. Carbon element diffusion causes saturation of martensite with this element. Hence, retained austenite amount of steel decreases and martensite amount increases too much.

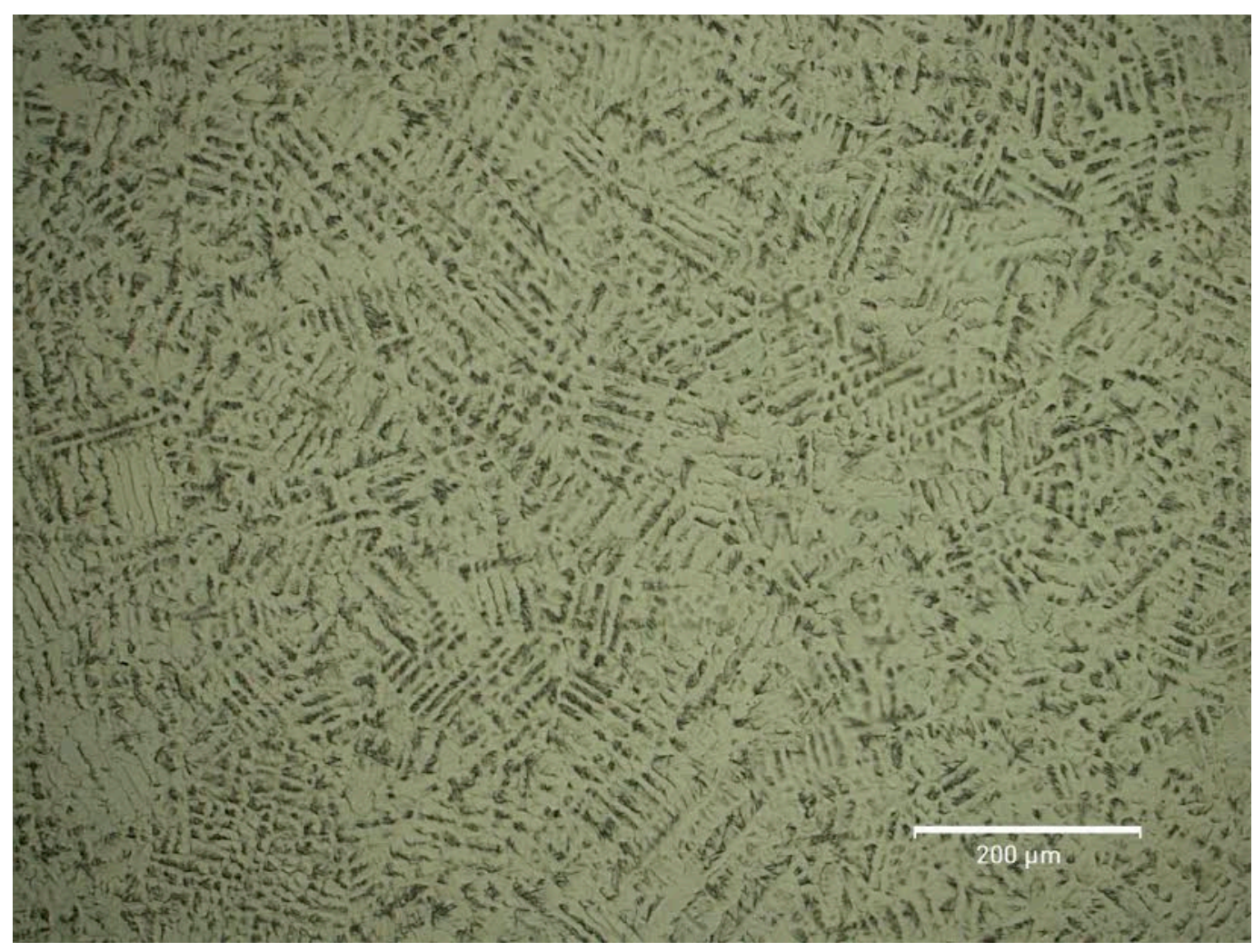

Figure 5. As- cast microstructure of steel 


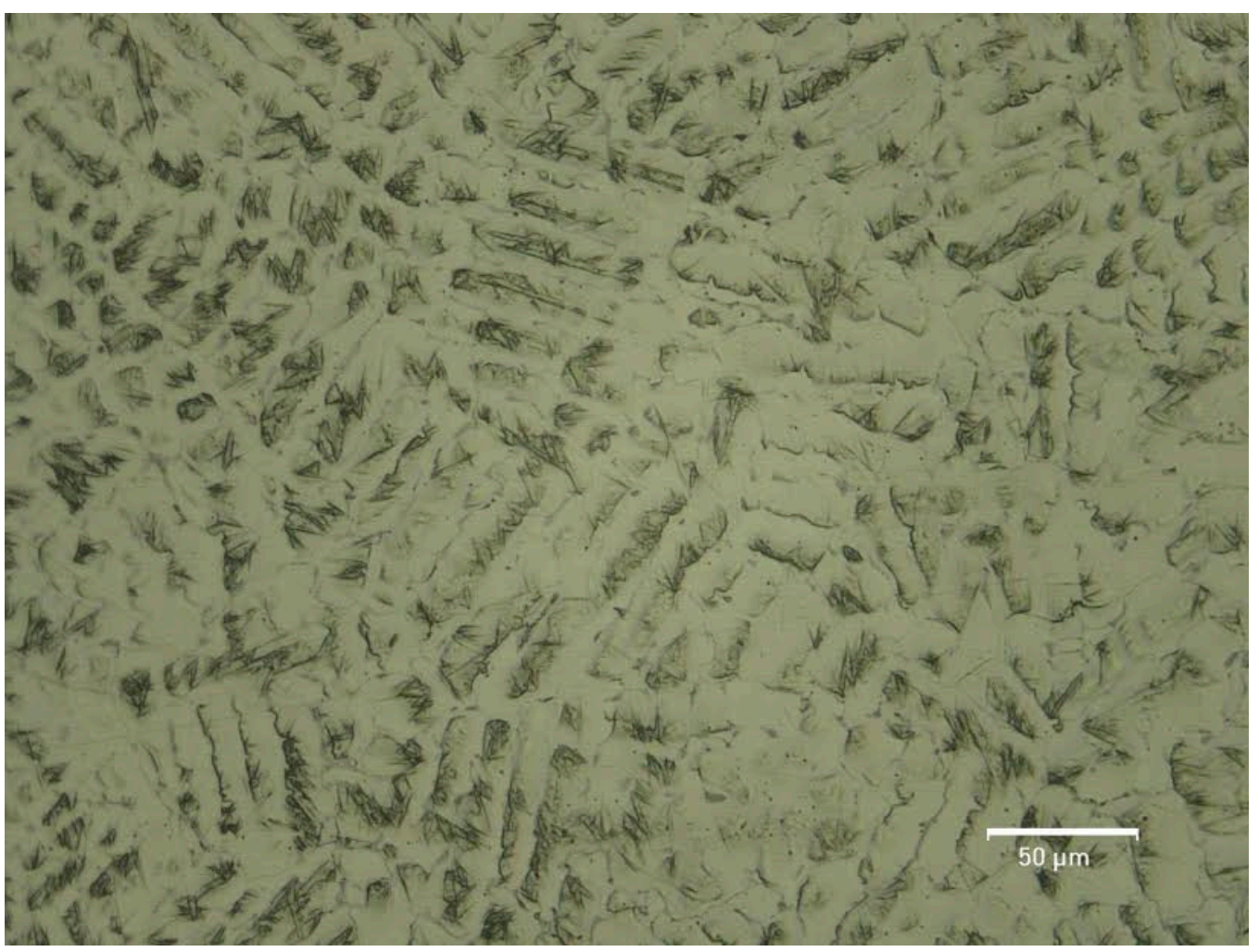

Figure 6. As- cast microstructure of steel (high magnification)

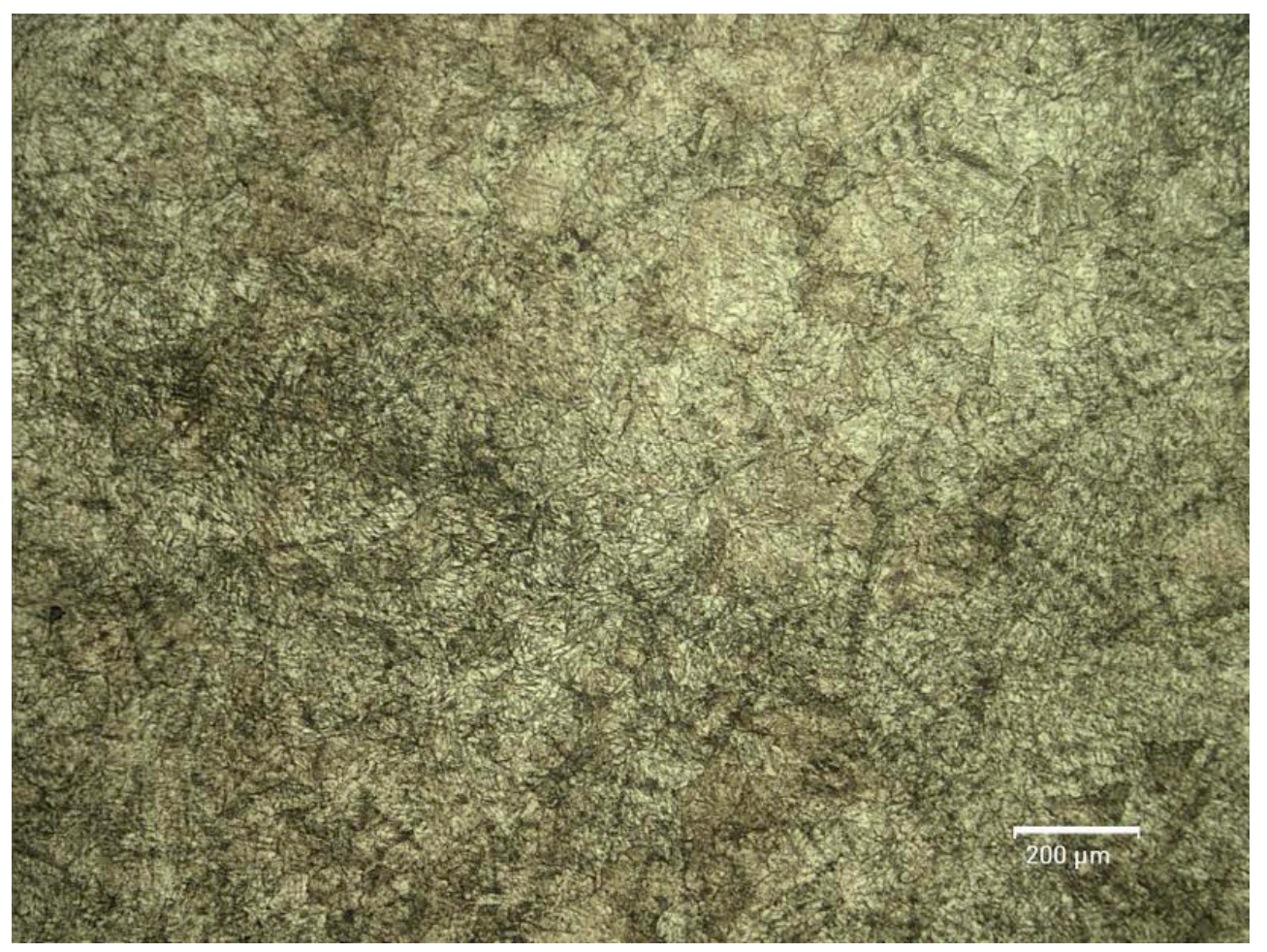

Figure 7. As- rolled microstructure of steel 


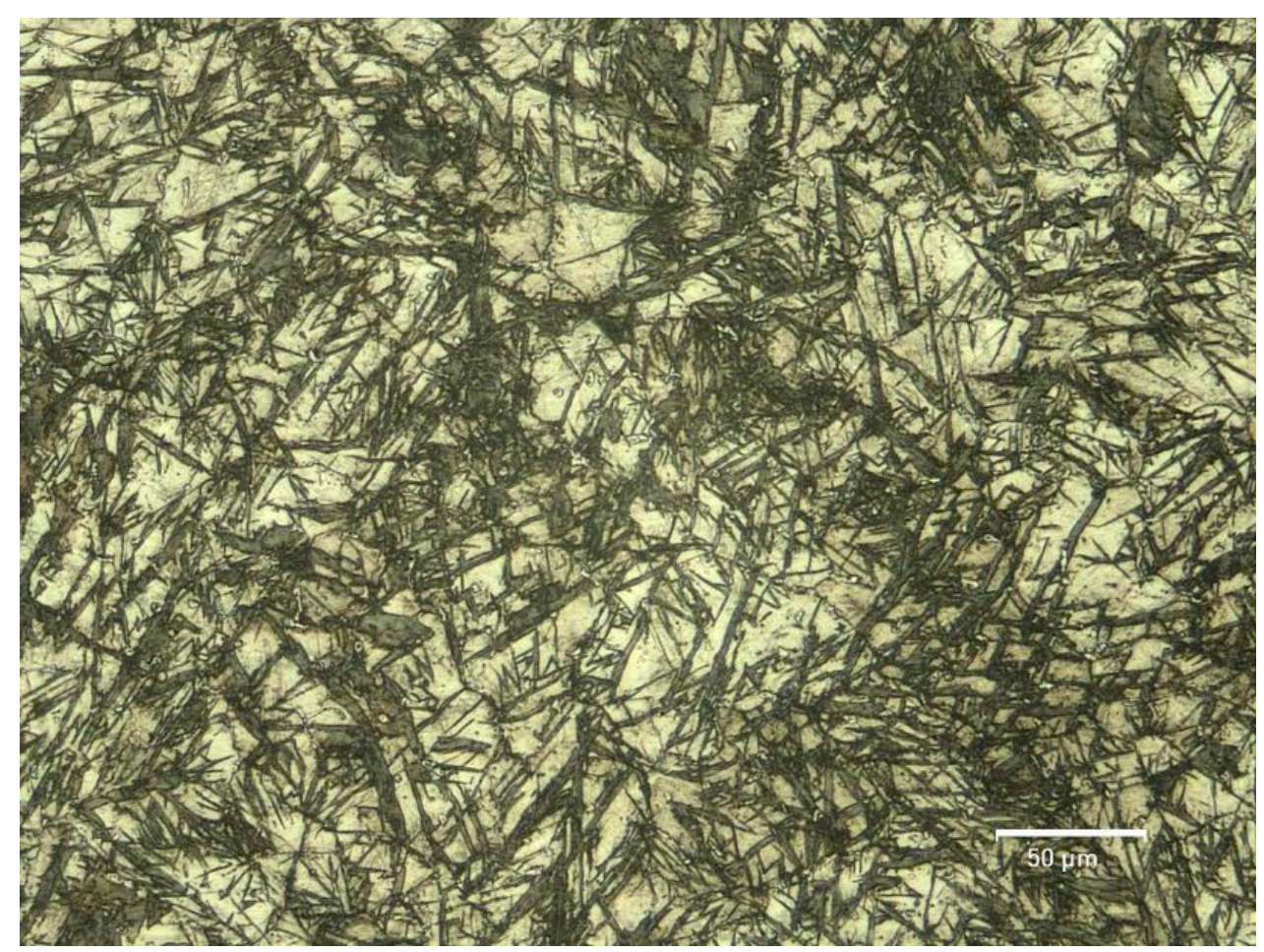

Figure 8. As- rolled microstructure of steel (high magnification)

Optical micrograph of commercial steel austenitized at $1025{ }^{\circ} \mathrm{C}$ for 1 hour (Figure 9) shows that microstructure consists of large and coarse primary carbides and martensite matrix. Hot rolling causes these carbides possesing a banding structure. Moreover, these coarse primary carbides are very stable and dissolves completely in matrix at high austenitizing temperatures [8]. New steel is entirely free of large and coarse carbides. White regions seen at optical micrograph of new steel austenitized at $1025{ }^{\circ} \mathrm{C}$ for 1 hour (Figure 10) is retained austenite and dark regions is martensite phase. The volume of retained austenite at new steel and commercial steel which are austenitized at $1025^{\circ} \mathrm{C}$ for 1 hour about $25,56 \%$ and $16,22 \%$ respectively. Because of higher amount of dissolving carbides in matrix during austenitizing, the volume of retained austenite at new steel is higher than the commercial steel. 


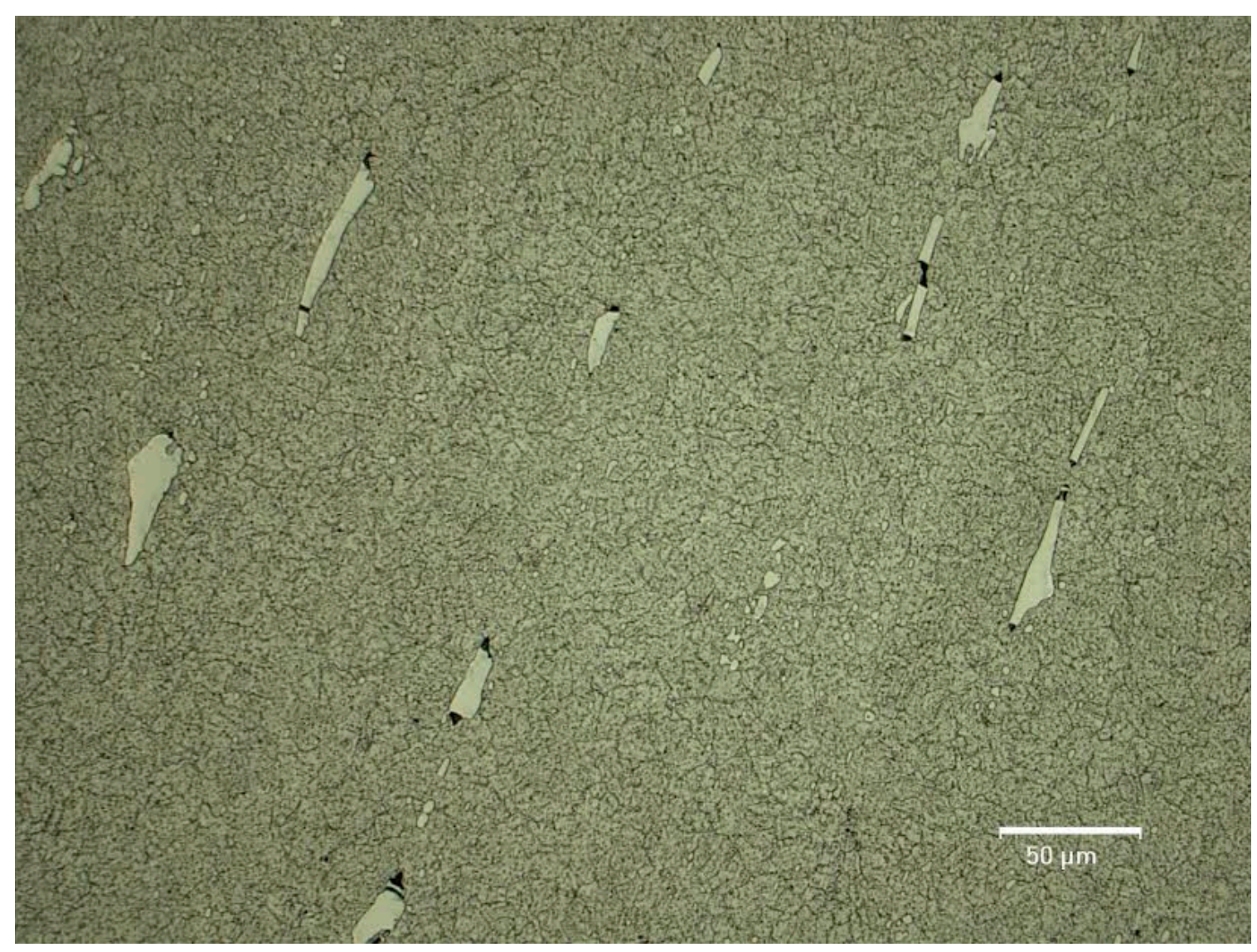

Figure 9. Microstructure of commercial steel austenitized at $1025{ }^{\circ} \mathrm{C}$ for 1 hour 


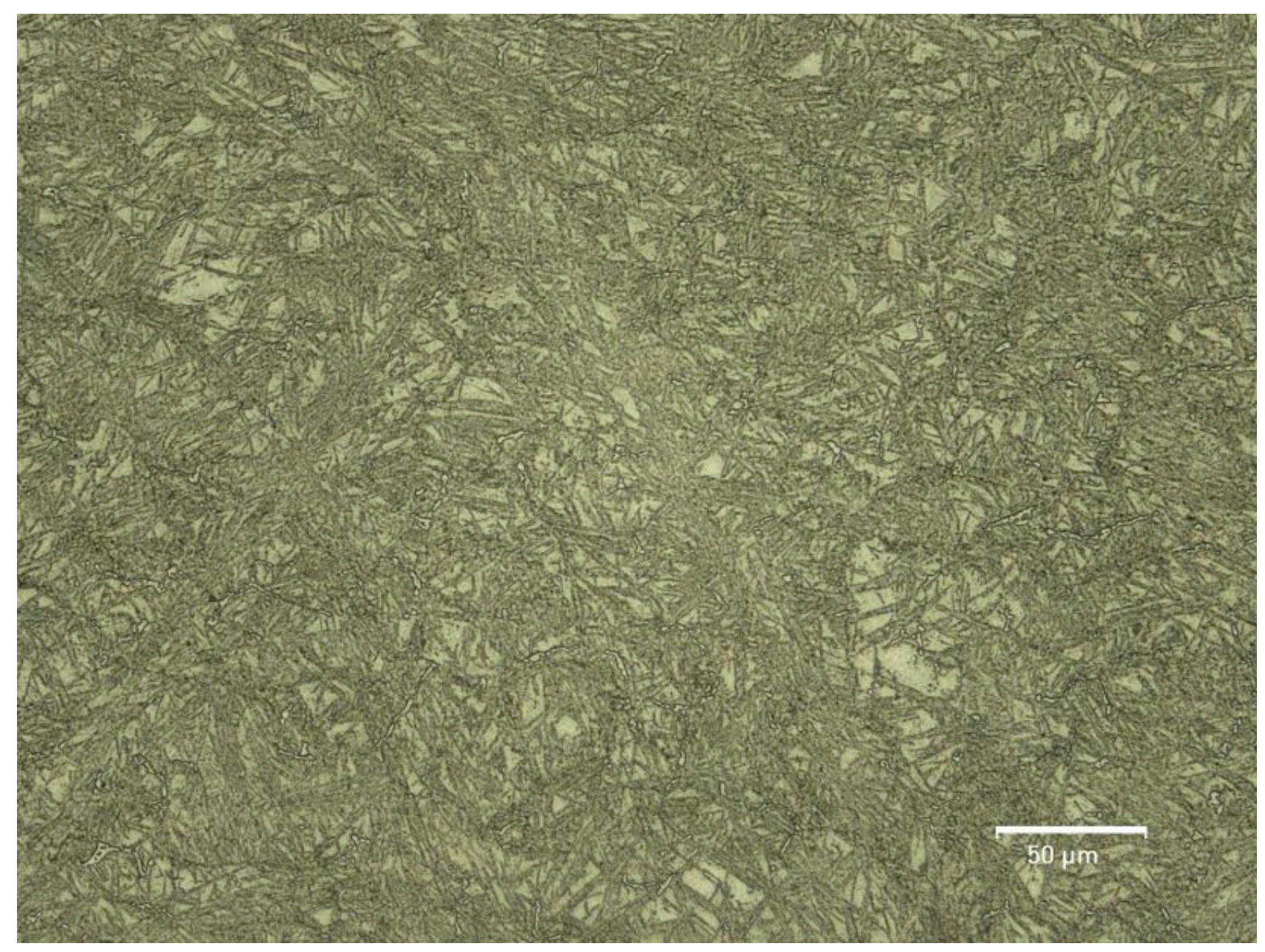

Figure 10. Microstructure of steel austenitized at $1025^{\circ} \mathrm{C}$ for 1 hour

Optical micrographes of commercial steel austenitezed at $1025{ }^{\circ} \mathrm{C}$ for 1 hour and tempered twice at $525^{\circ} \mathrm{C}$ for 30, 60, 90 and 120 minutes (Figure 11,13,15 and 17) shows that microstructure consists of large and coarse primary carbides banding, new forming fine carbides and tempered martensitic and bainitic matrix. More fine and homogeneous microstructure of tempered martensite and bainite can be observed from optical micrographes of new steel austenitized at $1025{ }^{\circ} \mathrm{C}$ for 1 hour and tempered twice at $525{ }^{\circ} \mathrm{C}$ for $30,60,90$ and 120 minutes (Figure 12,14,16 and 18). The volumes of retained austenite of commercial steel austenitized at $1025{ }^{\circ} \mathrm{C}$ for 1 hour and tempered twice at $525{ }^{\circ} \mathrm{C}$ for $30,60,90$ and 120 minutes are about $2,72 \%, 1,17 \%, 0 \%$ and $0 \%$ respectively. The volumes of retained austenite of new steel austenitized at $1025^{\circ} \mathrm{C}$ for 1 hour and tempered twice at $525{ }^{\circ} \mathrm{C}$ for $30,60,90$ and 120 minutes are about $8,96 \%, 2,43 \%, 1,55 \%$ and $0 \%$ respectively. 


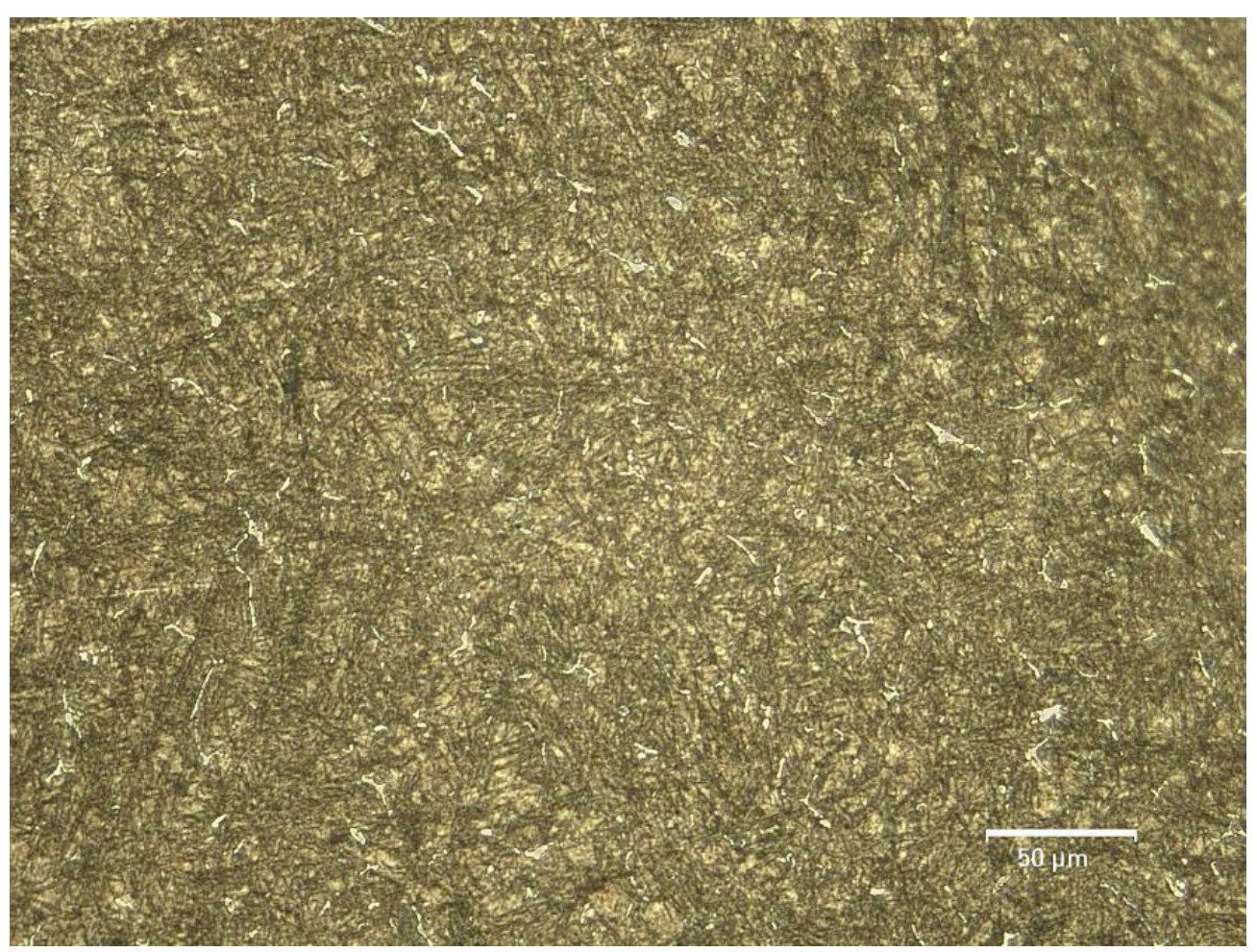

Fig 11. Microstructure of steel austenitized at $1025^{\circ} \mathrm{C}$ for 1 hour and tempered twice at 525 ${ }^{\circ} \mathrm{C}$ for 30 minute

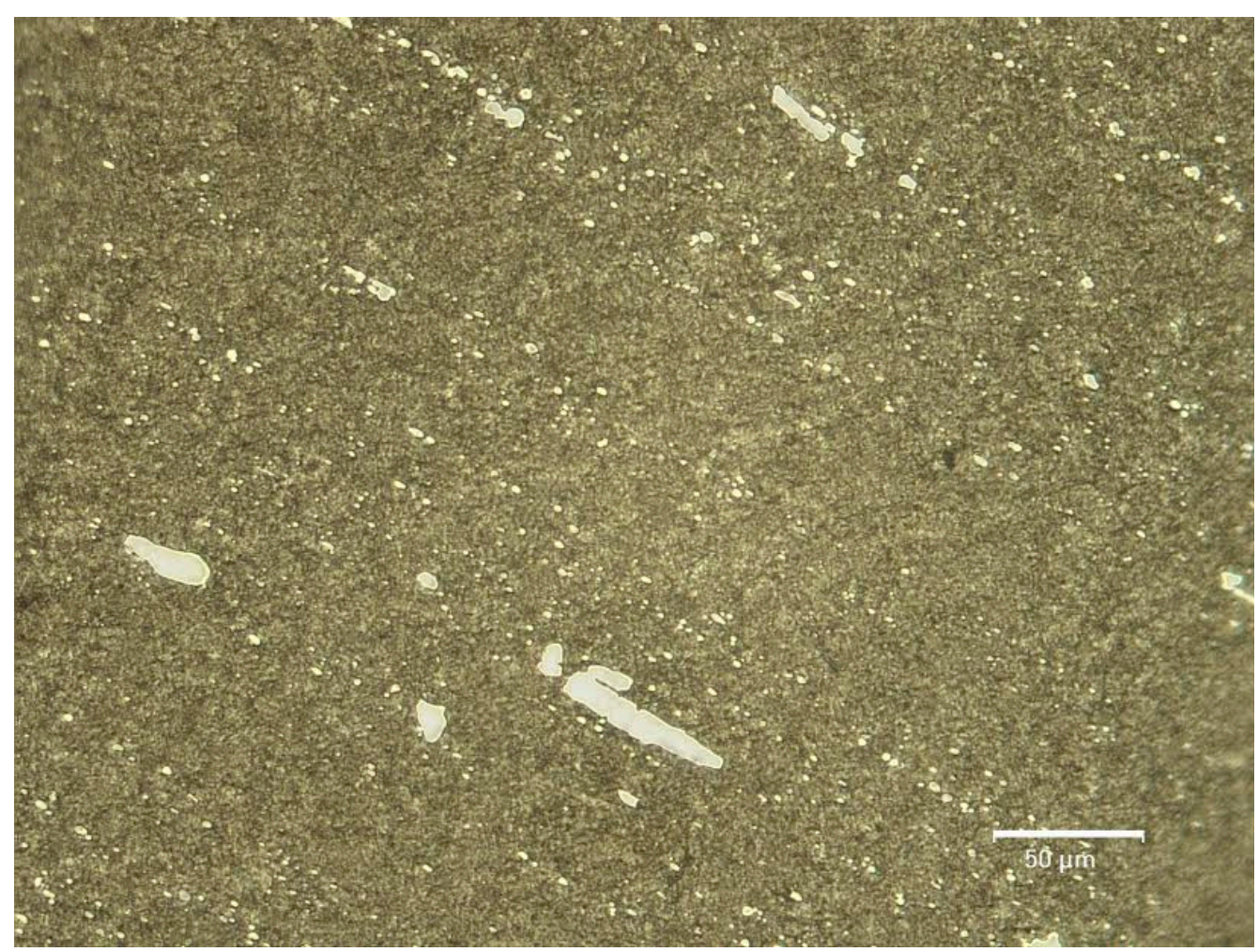

Fig 12. Microstructure of commercial steel austenitized at $1025^{\circ} \mathrm{C}$ for 1 hour and tempered twice at $525^{\circ} \mathrm{C}$ for 30 minute 


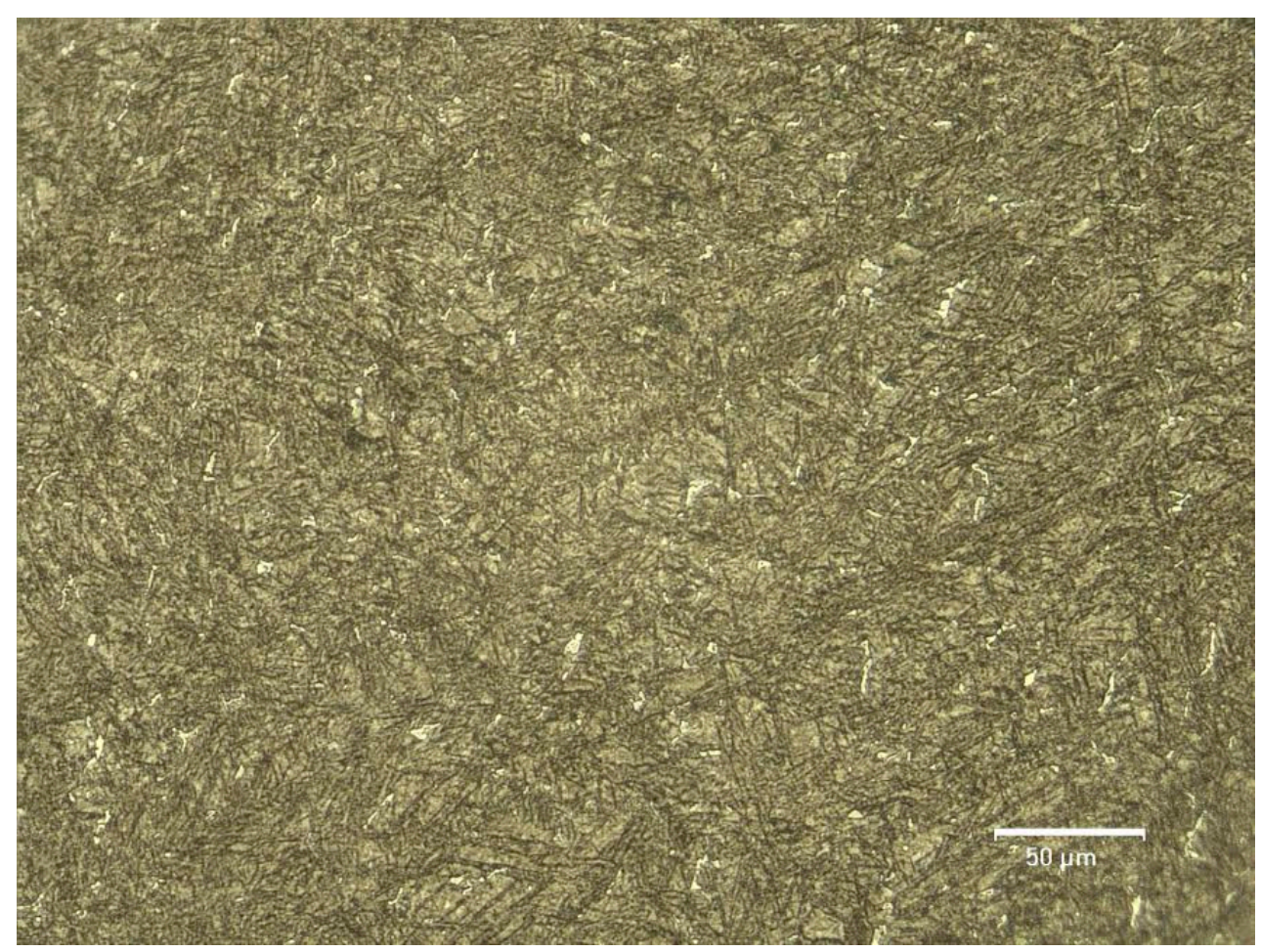

Fig 13. Microstructure of steel austenitized at $1025^{\circ} \mathrm{C}$ for 1 hour and tempered twice at 525 ${ }^{\circ} \mathrm{C}$ for 60 minute

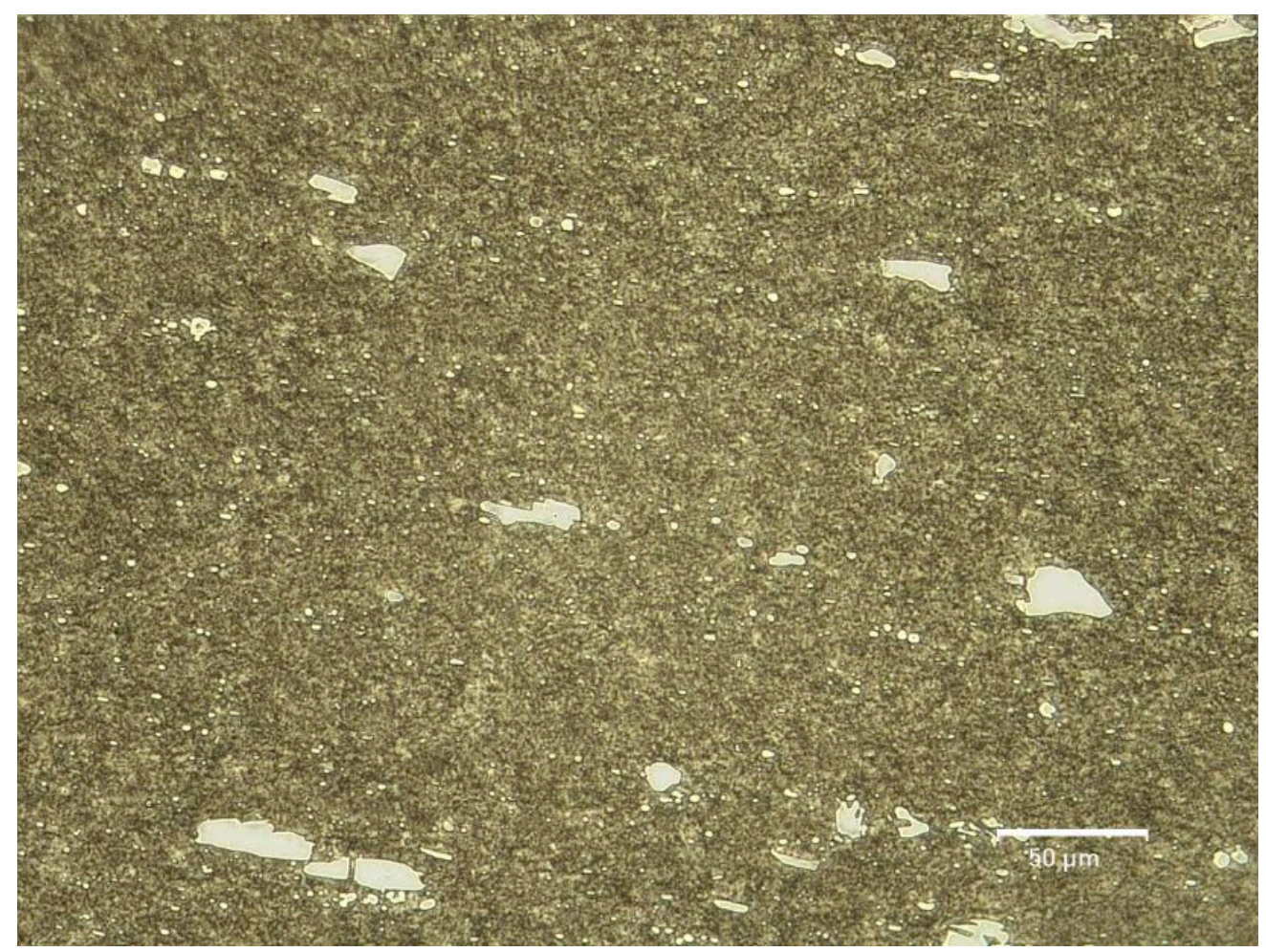

Fig 14. Microstructure of commercial steel austenitized at $1025^{\circ} \mathrm{C}$ for 1 hour and tempered twice at $525{ }^{\circ} \mathrm{C}$ for 60 minute 


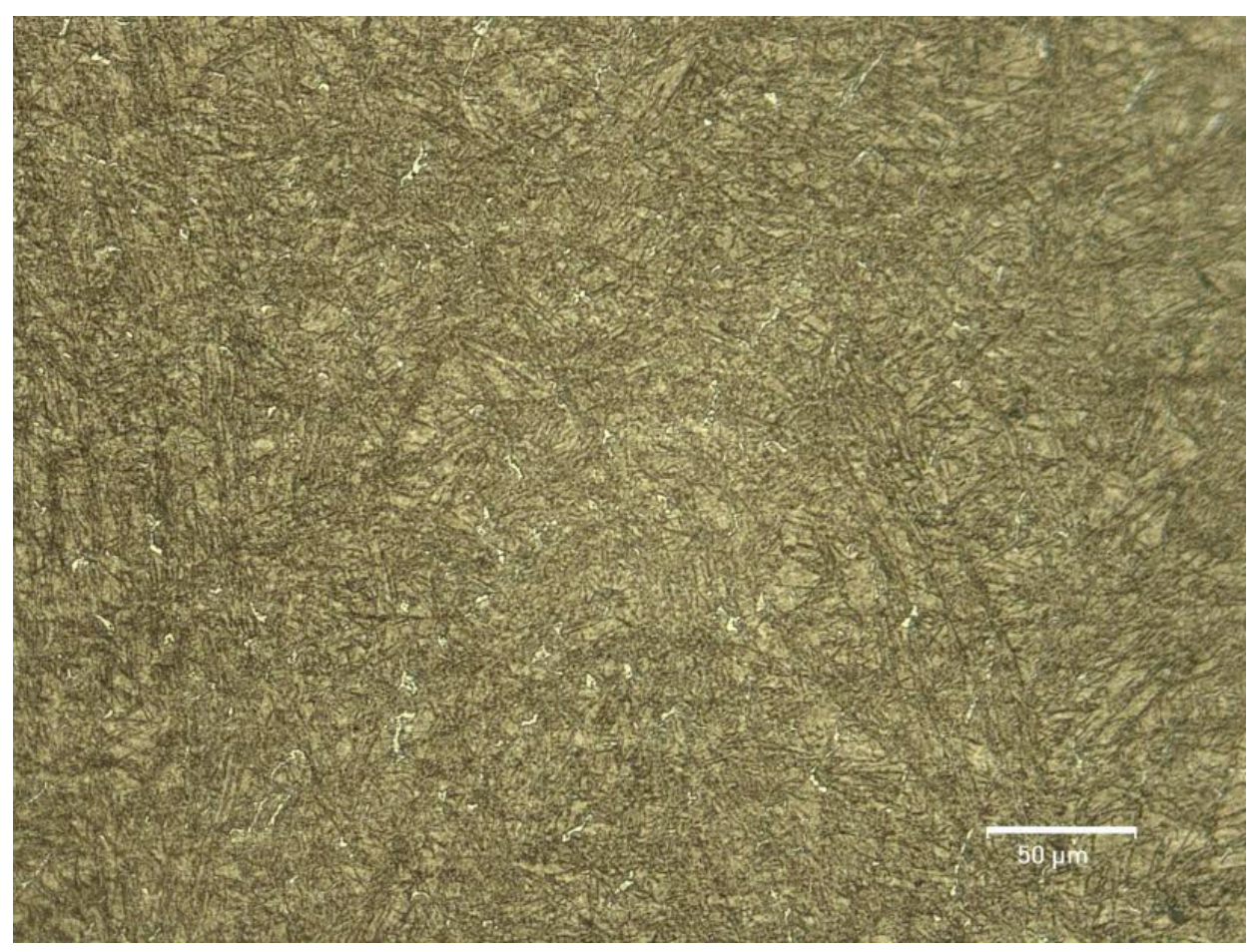

Fig 15. Microstructure of steel austenitized at $1025^{\circ} \mathrm{C}$ for 1 hour and tempered twice at 525 ${ }^{\circ} \mathrm{C}$ for 90 minute

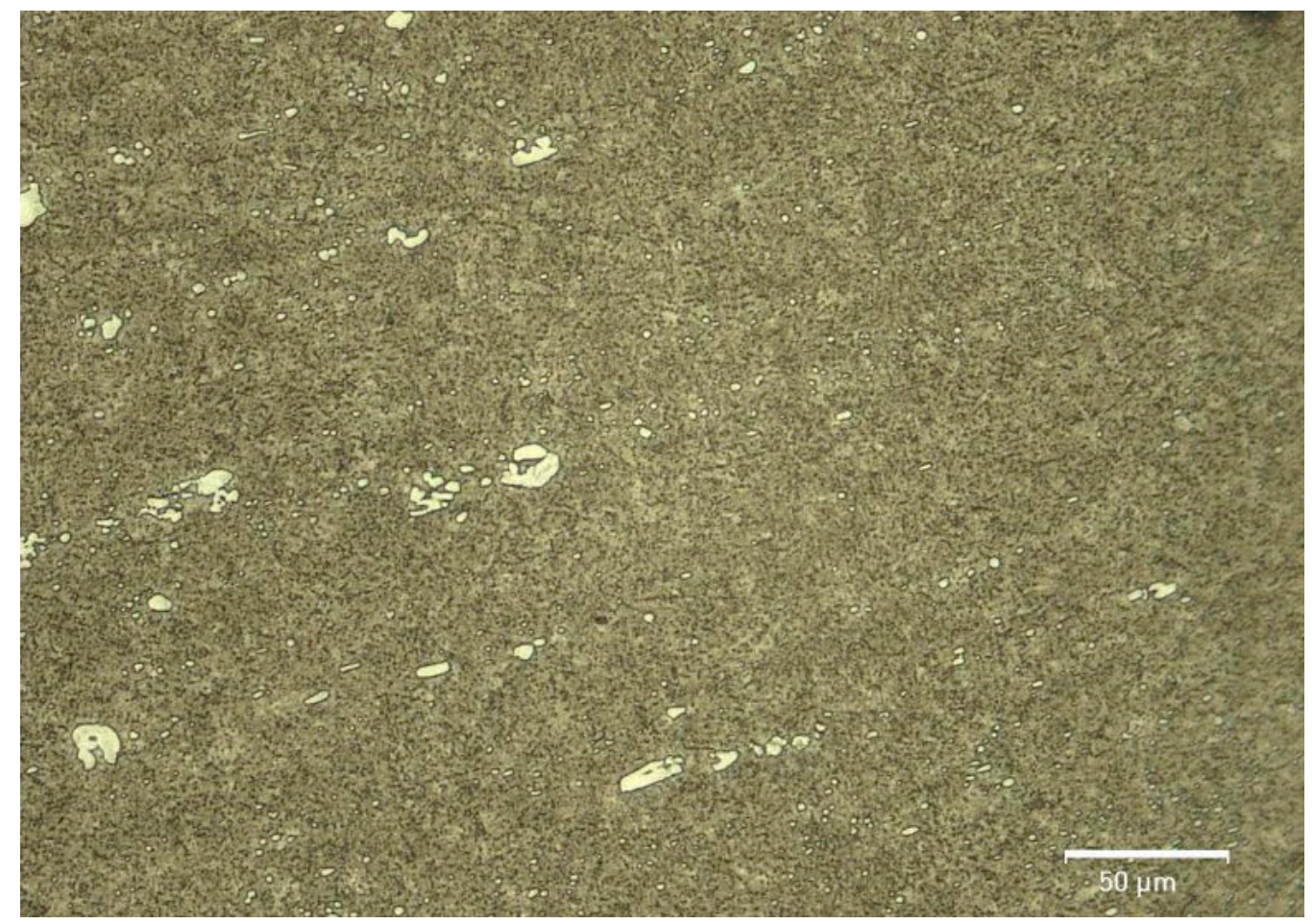

Fig 16. Microstructure of commercial steel austenitized at $1025^{\circ} \mathrm{C}$ for 1 hour and tempered twice at $525^{\circ} \mathrm{C}$ for 90 minute 


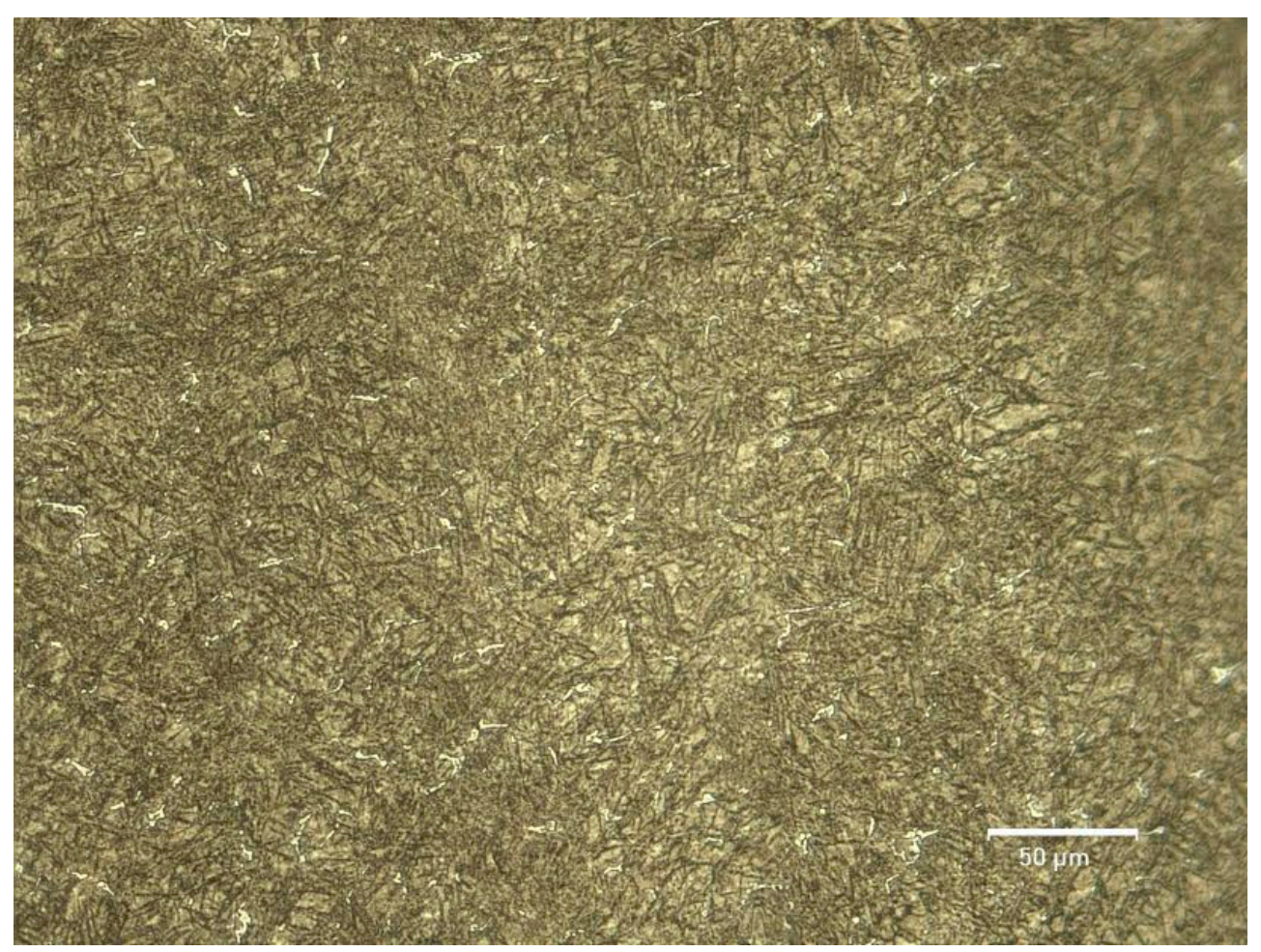

Fig 17. Microstructure of steel austenitized at $1025^{\circ} \mathrm{C}$ for 1 hour and tempered twice at 525 ${ }^{\circ} \mathrm{C}$ for 120 minute

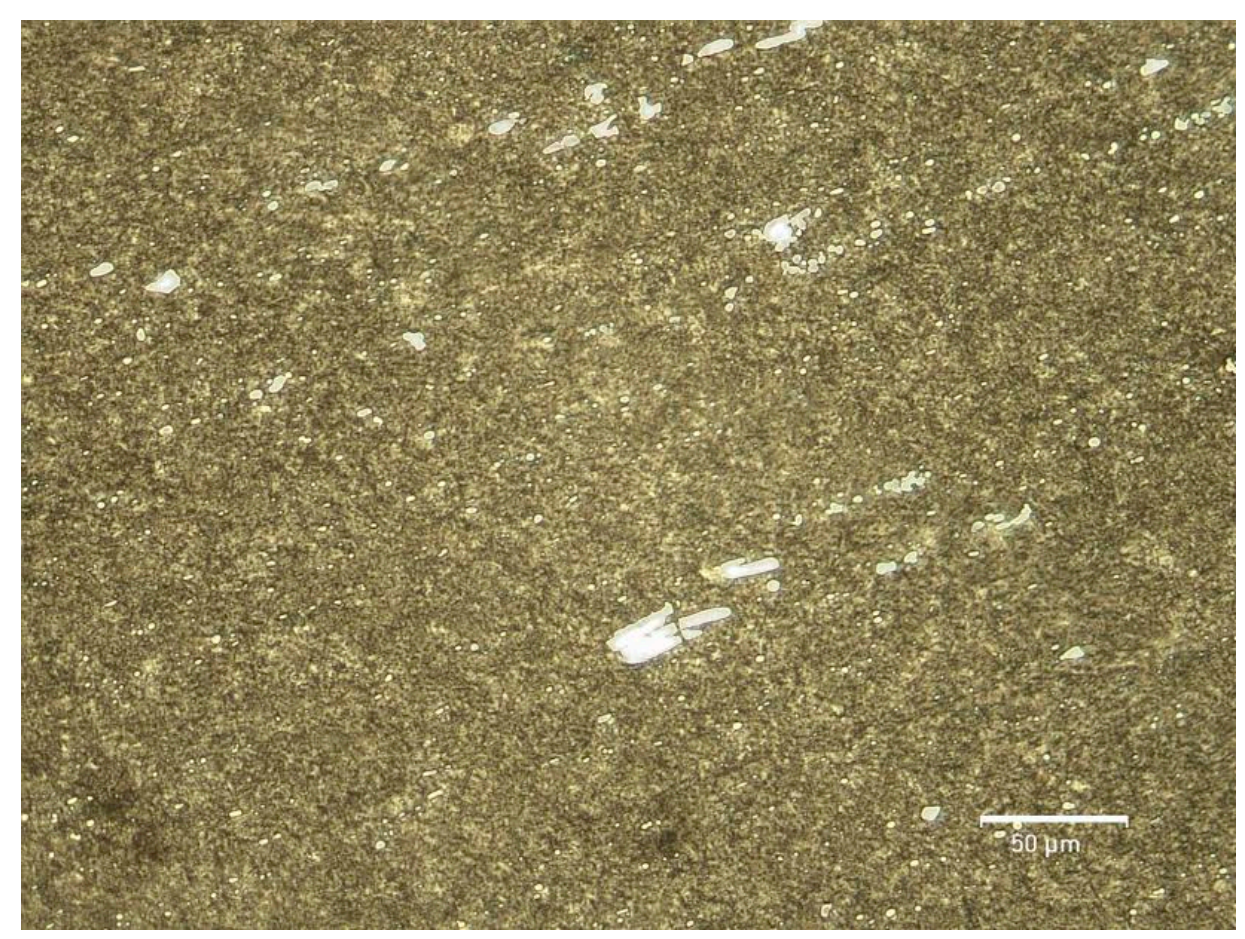

Fig 18. Microstructure of commercial steel austenitized at $1025^{\circ} \mathrm{C}$ for 1 hour and tempered twice at $525^{\circ} \mathrm{C}$ for 120 minute 


\subsection{Hardness}

Hardness decreases for two steels (new steel and commercial one) up to 60 minutes double tempering. Hardness of new steel increases after 60 minute because of secondary hardnening phenomena. Secondary hardnening is observed for commercial steel after 90 minute double tempering. High volume percentage of dissolving carbon atoms in matrix instead of forming carbides at new steel, secondary hardening behaviour and hardness values of new steel are higher than that of commercial steel for all tempering times.

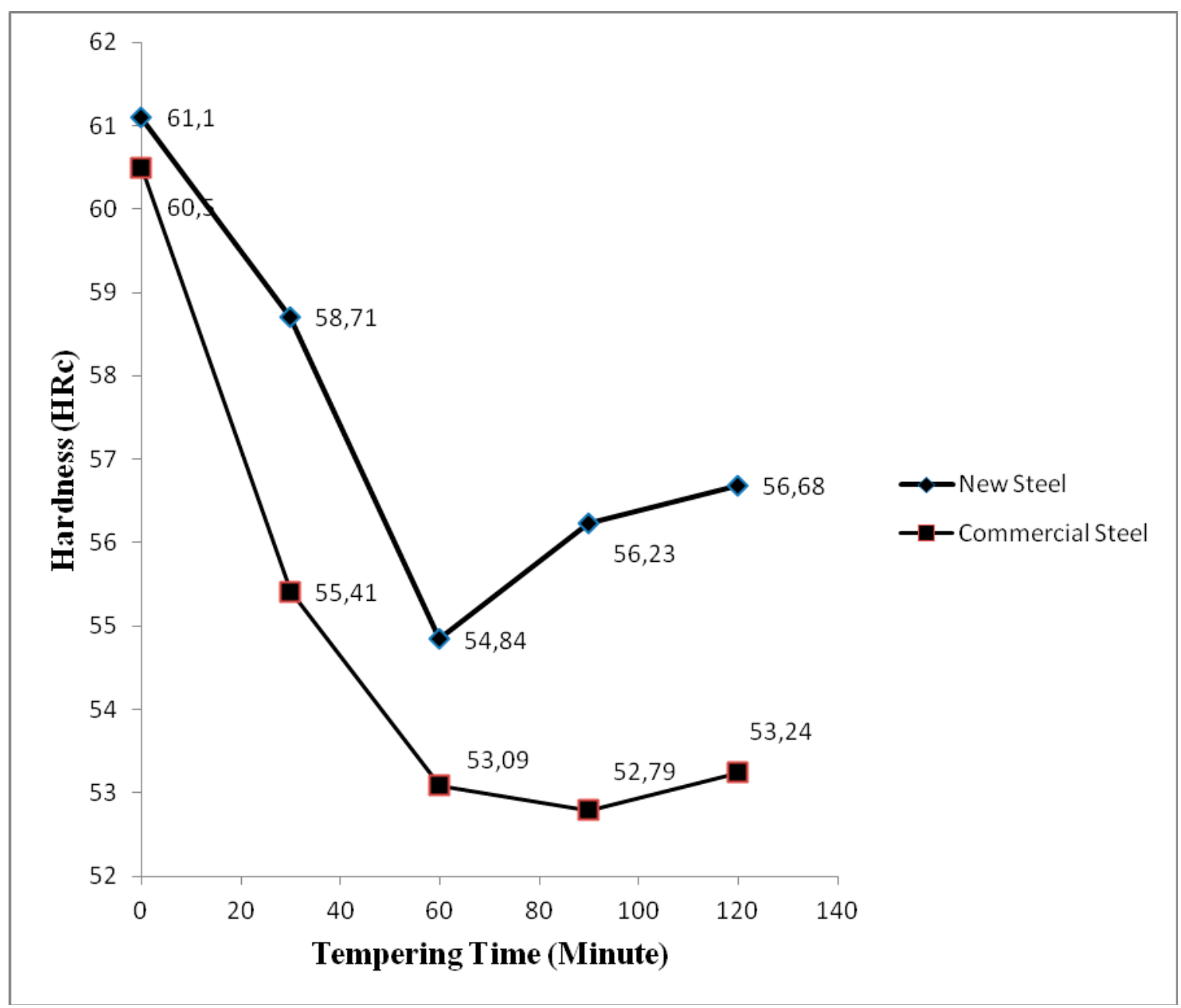

Figure 19. Hardness values of new steel and commercial one after tempering heat treatments.

Conflicts of Interest: The authors declare no conflict of interest. 


\section{Conclusions}

Experiments have shown that the properties of new rapid solidified steel have more homogeneous microstructure and higher hardness values than commercial produced DC 53 steel. Therefore, the new proposed method can be used as an alternative manufacturing method for more tough cold-work tool steel. Besides, after experiment it can be concluded that:

(1) High solidification rates caused a large amount of metastable (or residual) austenite present in the steel at room temperature and fully free of coarse and large primary carbides.

(2) High solidification rates caused primary carbides nucleating beside the existent solid phases not having time to grow and they became fine and distributed homogeneously.

(3) After austenitizing at $1025{ }^{\circ} \mathrm{C}$ for one hour of commercial DC 53 steel, large and coarse primary carbides exist still in matrix.

(4) High solidification rates caused dissolving more carbon atoms in matrix instead of forming carbides and after tempering of two steel, hardness values of new steel are higher than that of commercial steel for all tempering times.

\section{References}

1- K. Fukaura, Y. Yokoyama, D. Yokoi, N. Tsujii, K. Ono, Metall. Mater. Trans. A, 35 (2004), pp. 1289-1300

2- H. X. Chi, D. S. Ma, Q. L. Yong, L. Z. Wu, Z. P. Zhang and Y. W. Wang, J. of Iron and Steel Research Vol. 17(6), (2010)

3- P. S. Babu, P. Rajendran and K. N. RAO, Int. J. Mater. Sci., Vol. 210, (2010)

4- Tiziani A, Molinari A. Materials Science and Engineering, 1988. 101A: 125.

5-M. N. Mohammed, M. Z. Omar, J. Syarif, Z. Sajuri, M. S. Salleh, and K. S. Alhawari, The Scientific World Journal, Volume 2013 (2013), Article ID 828926

6- A.Polat, F. Ozturk, S. Toros, International Iron \& Steel Symposium, Karabük, Türkiye 2012, pp.910-915

7- Hyoung-Seok Park, Jae-Bok Seol, Nam-Suk Lim, Sung-Il Kim and Chan-Gyung Park Journal: Materials \& Design, 2015, Volume 82, Page 173

8- Y. Zhang, H. Han, L. Miao, H. Zhang, J. Fi, Mater. Trans. 50A, 2507 (2009)

(C) 2017 by the authors; licensee Preprints, Basel, Switzerland. This article is an open access article distributed under the terms and conditions of the Creative Commons by Attribution (CC-BY) license (http://creativecommons.org/licenses/by/4.0/). 